\title{
WACANA BENTURAN PERADABAN DALAM NOVEL THE SATANIC VERSES KARYA SALMAN RUSHDIE
}

\author{
oleh Moch. Ali \\ FS Universitas Airlangga Surabaya
}

\begin{abstract}
This article is about a research describing a discourse on the clash of civilizations represented in the person of Mahoud, the Hellenized Islamic prophet in the pejorative novel of the Western World The Satanic Verses by Salman Rushdie, who was born in the Bharrat tradition of India. As a famous novel in that world, The Satanic Verses politically represents a hegemony in discourse of a secretive quantum literary industry to create a clash in civilization between the East and the West through a deconstuction of religious power.

The research employs a descriptive qualitative technique in the data analysis, which is textually done by understanding (1) the position of Salman Rushdie as a Indian-English author toward the well-known Islamic religious symbols in creating the representation and (2) his way in representing Mahoud the prophet in the novel.

The research uses Stuart Hall's and Michel Foucault's theory of representation. As a result, the analysis shows that The Satanic Verses as a novel by an author of Indian and English blood offers a literary discourse as an imaginative political manisfesto through the projection of language power. Obviously, the imaginative discourse also shows how the Indian-English author has an absolute control over the literary language play used in the representation of religious symbols.
\end{abstract}

Keywords: Bhãrat, the West, Islam, Indian-English author, The Satanic Verses

\section{A. PENDAhUluan}

Gaung sang maestro sastra dunia, sekaligus novelis Indo-Inggris asal India (Bhārat), Salman Rushdie dengan novelnya The Satanic Verses, seakan menjadi 'icon' sederetan karya novel lain yang menandai tonggak genre sastra phantasmagoria dengan mengusung ide anti-logia sacra sebagai simbol perlawanan budaya mapan. Sebut saja misalnya; karya novelis Thomas Paine (1737-1809) yang berjudul The Age of Reason, The Last Temptation of Christ (1955) karya Nikos Kazantzakis, The Da Vinci Code (2004) karya Dan Brown, Toledot Yeshu' ha-Notzri karya Chaim Nachman Bialik (1873-1934) yang ditulis dalam bahasa Ibrani, Langit Makin Mendung (1968) karya Kipandjikusmin,
Balsafah Gatholoco karya Prawirataruna, Serat Darmogandul karya Ki Kalamwadi, juga yang lagi hangat di Bangladesh, berjudul Lajja karya Taslima Nasreen yang dijuluki sebagai Salman Rushdie Betina; semuanya didakwa sebagai karya sastra popular yang melecehkan sakralitas agama. Kalau The Age of Reason, The Last Temptation of Christ, The Da Vinci Code dan Toledot Yeshu' ha-Notzri dianggap sebagai karya sastra yang melecehkan pewahyuan Bible dan menelanjangi 'pribadi' Yesus Kristus, begitu juga Langit Makin Mendung, Balsafah Gatholoco, Serat Darmogandul, dan Lajja juga divonis sebagai karya sastra yang 'menginjakinjak kehormatan' Islam, pewahyuan AlQur'an, dan mencerca 'pribadi' Nabi Muhammad. Fenomena sastra phantasmagoria 
yang terbentang sejak abad Pertengahan hingga zaman post-modern, menurut peneliti pasti bersifat laten dan akan terus berinkarnasi. Dengan modus operandi yang sangat khas yang kebanyakan bercirikan anti-logia sacra ternyata secara inheren selalu memanfaatkan 5 elemen penciptaan karya sastra yang bersifat niscaya; (1) adopsi, (2) adaptasi, (3) intertekstualitas, (4) transformatif, dan (5) imajinatif yang ujung-ujungnya mengemban amanat ganda; desakralisasi dan polemik.

Dalam penelitian ini, peneliti lebih memfokuskan kajian pada karya sastra ternama The Satanic Verses yang secara diakronis melintas zaman, menghenyakkan religiositas tataran grassroots dan elit kaum agama, serta eksistensinya menyeret dimensi politis. Oleh karena itu, tidak salah bila hingga hari ini karyakarya popular yang sejenis, seperti The Satanic Verses ini masih diapresiasi secara serius oleh kalangan budayawan maupun agamawan untuk menelanjangi diskursus keagamaan yang taken for granted bahkan terkesan ipse dixit. Dengan gaya naratif dan dialogis, pengarang mengkritik wacana keagamaan status quo yang selalu ditaqdis-kan, dan pada saat yang sama memarginalkan pemahaman yang lain. Selain itu, karya ini unik bila ditilik dari ranah antilogia sacra. Agaknya, salah satu dari karya sastra Indo-Inggris ini juga mengusung ideologi resistensi yang menghantam ideologi status-quo sebagaimana Serat Darmogandhul yang pernah menggegerkan pasar wacana pemikiran Jawa. Jika The Satanic Verses lahir dari budaya Muslim-dālit India yang tercerabut dari akar religiositas Islam dan mengalami pembaratan bahkan keterasingan "tanpa iman" (without faith), sebaliknya Serat Darmogandhul lahir dari budaya Muslimpriyayi Jawa yang berekstase dalam akar religiositas Kejawen dan bahkan semakin kukuh dalam beriman a la Kejawen, atau lebih popular disebut orgasme "makin beriman" (orgasm within faith). Lalu, apa sebenarnya kekhasan karya Salman Rushdie tersebut berkaitan dengan 'konsep pemikiran'? Menurut peneliti, paling tidak dapat dikatakan bahwa novel the Satanic Verses sebagai karya sastra
Indo-Inggris merepresentasikan model 'pemikiran Barat dalam kemasan kultur Bhārat', atau bisa juga merepresentasikan model 'pemikiran Barat dalam kemasan kultur Islam.'

Berdasarkan latar belakang masalah di atas, permasalahan yang dikaji adalah (i) memahami posisi Salman Rusdhie sebagai pengarang karya sastra Indo-Inggris dalam menciptakan representasinya untuk melawan simbol-simbol keagamaan Islam yang telah berterima dalam ranah pemikiran pemeluknya, (ii) memahami cara Salman Rusdhie merepresentasikan Mahound sang nabi dalam novel polemiknya.

Stuart Hall (1997:16-17) mendefinisikan 'representasi' sebagai upaya penciptaan makna tentang konsep-konsep dalam pikiran melalui wahana bahasa. Penciptaan makna tersebut bukanlah merujuk pada konsep-konsep yang hampa makna, tetapi justru lebih mengacu pada pemarjinalan makna yang terberi dan menggantinya dengan makna liyan. Tentu saja injeksi makna ini didasarkan pada faktor ideologis pengarang yang bertujuan untuk menghadirkan makna versi-versi lain tentang yang direpresentasikan dalam korpus ketegangan atau pun benturan budaya. Oleh karena itu, menurutnya, aspek terpenting dalam representasi mengacu pada dua hal; (i) representative, merujuk pada 'yang merepresentasikan', (ii) represented, merujuk pada 'yang direpresentasikan.' Dengan demikian, sang representatif mempunyai kuasa untuk menampilkan apa yang ingin dihadirkan sesuai dengan persepsinya.

Anggitan penciptaan makna dalam representasi melalui wahana bahasa tersebut akan berhasil bila digunakan pendekatan yang tepat, yakni pendekatan konstruksionis. Pendekatan ini bertujuan untuk membongkar teks, sebab makna yang terberi dalam teks dipandang sebagai sebuah konstruksi ideologis yang sifatnya mapan sebagai hasil rekayasa sosial tertentu yang meniscayakan adanya sistem konsep dari budaya yang mengkonstruksi makna itu sendiri. Dalam ranah budaya itulah, wacana yang beroperasi pada berbagai variasi teks yang telah mapan 
justru menempatkan representasi sebagai sumber produksi pengetahuan (Hall, 1997:25). Pendekatan konstruksionis ini tentu saja serupa dengan konsep representasi yang dikemukakan oleh Michel Foucault. Foucault mengatakan:

'representation is the production of knowledge through discourse ....... discourse itself is the group of statements which provide a language for talking about a way of representing the language about a particular topic at a particular historical language. (Foucault in Hall, 1997:42-43)

Foucault juga menekankan pentingnya wacana dalam proses penciptaan makna. Baginya, makna rekonstruksionis tidak dapat dihadirkan di luar wacana, sebab tidak ada yang bermakna di luar wacana. Dengan demikian, representasi merupakan pemerian makna sebagai rekayasa ulang pelaku budaya terhadap wacana yang telah terberikan makna; dan komunitas dalam ranah budayalah yang memaknainya. Inilah yang disebut 'pengetahuan yang dipilih' sebagai upaya selected judgment untuk menunjang imaji kekuasaan dalam pengetahuan yang di dalamnya sang pengarang terlibat secara langsung sebagai upaya kreatifitas membangun 'konsep liyan' untuk menciptakan wacana benturan budaya/ peradaban.

\section{B. METODE PENELITIAN}

Sumber data dalam penelitian ini adalah (i) komentar, pandangan, atau pun wawancara Salman Rusdhie tentang jatidiri dan novel-novelnya dalam catatan jurnalis Eropa, (ii) novel The Satanic Verses karya Salman Rushdie sendiri. Pemerolehan data penelitian dilakukan dengan dua cara, yakni pembacaan intensif dan pencatatan. Pembacaan intensif dilakukan dengan cara membaca teks secara berulang-ulang, baik teks yang berupa laporan investigatif maupun teks sastra yang terekam dalam novel polemik sang sastrawan agar dapat diperoleh keakuratan data. Menurut Atar Semi (1993:25), penelitian kualitatif penting diterapkan dalam ranah penelitian karya sastra, sebab penelitian model ini lebih mengutamakan kedalaman penghayatan terhadap interaksi antar konsep yang sedang dikaji secara empiris. Oleh karena itulah, dalam menganalisis teks novel karya Salman Rusdhie ini, peneliti menggunakan teknik deskriptif kualitatif.

Sesuai dengan permasalahan yang ada, analisis yang dilakukan berkaitan dengan dua hal; (i) posisi Salman Rusdhie sebagai pengarang karya sastra Indo-Inggris dalam menciptakan representasinya untuk melawan simbol-simbol keagamaan Islam yang telah berterima dalam ranah pemikiran pemeluknya, (ii) cara Salman Rusdhie merepresentasikan Mahound sang nabi dalam novel polemiknya.

\section{HA S I L P N EL I T IAN DAN PEMBAHASAN}

Berdasarkan tujuan penelitian, berikut ini disajikan hasil penelitian dan langsung diikuti dengan pembahasannya

\section{Posisi Salman Rusdhie sebagai pengarang karya sastra Indo-Inggris}

Salman Rushdie, lahir pada tanggal 19 Juni 1947, dengan nama kecil Salman Sinai, dalam sebuah keluarga Muslim-dālit yang mendadak kaya raya di Mumbai. Menurut John I. Razu Mohan (dalam Mucha-Shim Arquiza dan M. Abdus Sabur, 2001:114), istilah dālit dalam bahasa Sansekerta bermakna komunitas Hindu yang tak berkasta. Dengan demikian, komunitas Muslim-dālit merupakan suatu pelabelan komunitas Hindu yang terkonversi dalam agama Islam. Dalam ajaran Hindu di India, strata dālit merupakan strata terendah di luar empat kasta varnāśrama - menurut ajaran Weda; brāhmana, ksatriya, śüdra, dan vaiśya. Kehidupan komunitas dālit amat miskin, tinggal di tempat-tempat kumuh, serta tidak dapat bersosialisasi dengan kasta-kasta yang lain. Kebanyakan mantan Hindu di India yang beralih memeluk agama Islam berasal dari strata dālit ini. Namun, setelah memeluk Islam, strata sosial mereka meningkat yang dalam realitas sosial kedudukannya sederajat dengan strata-strata yang lain; sehingga mereka bisa 
berbisnis dengan siapapun dan dari kalangan manapun. Meskipun domain keagamaan mereka berubah secara ideologis, tetapi secara biologis pelabelan Muslim-dālit dan Hindudālit tidak berubah. Fakta ini disebabkan adanya dikotomi differensial antara kognitif sosial dan realitas sosial. Sebagai bagian komunitas Muslim-dālit yang mendadak kaya, keluarga ini setiap hari selalu menggunakan bahasa Inggris dan Urdu dalam kehidupan mereka di rumah, tidak mustahil bila keluarga Rushdie terpandang sebagai keluarga terpelajar, dan pebisnis. Namun sayang, kakeknya yang memulai kekayaan famili itu, sangat terpukul menyaksikan anaknya sendiri, Anis Rushdie (w. 1986) menghamburhamburkan aset keluarga. Tapi, kakeknya tak tinggal diam, sang kakek yang pernah menggondol gelar dari King's Collage, Cambridge, menginginkan Salman Rushdie, cucu lelaki satu-satunya, kuliah di Rugby, Inggris, agar dapat mengikuti jejaknya sebagai pengusaha. Apalagi sejak kecil, Rushdie dikenal sebagai 'kutu buku' dan dapat diandalkan intelegensianya.

Ketika usia Salman Rushdie 13 tahun, ia dikirim ke Rugby. Namun, Rugby bukanlah kampus yang familiar, malah justru di sana ia merasakan keterasingan kultural, religi, bahkan ras, yang berujung pada episteme 'apartheid.' Pamflet dan coret-coretan di tembok yang menorehkan seni graffiti khas Barat selalu bernada rasialis yang selalu memaki orang Bhārat. Perasaan betah dan tidak betah bergelayut dalam pikirannya. Baginya, ia merasa dilecehkan tidak sebagai 'bukan manusia' tapi sebagai 'orang India'. Sindrom anti ras Bhārat ini benar-benar menyiksa pikirannya. Keterasingan dalam jiwa Rushdie makin 'menganga' tatkala ia melanjutkan studinya di bidang Sejarah di Cambridge, tahun 1964. Di kampus inilah ia banyak belajar bukubuku sejarah Islam dan Tarikh Nabi. Juga, saat itu, paham anti konservatisme, eksistensialisme, dan hedonisme sedang menuju puncak di kalangan pemikir Barat. Hasil wawancaranya dengan Brian Appleyard, wartawan The Sunday Times Magazine, 11
September 1988, ia menuturkan :

\begin{abstract}
"Sungguh menyenangkan waktu berada di Cambridge antara tahun 1965-1968. Di sana untuk pertama kalinya saya berkenalan dengan sex, obat bius, dan musik rock ' $n$ ' roll. Saya tidak lagi menjadi konservatif karena pengaruh perang Vietnam, dan kecanduan obat bius."
\end{abstract}

Sindrom keterasingan yang terinjeksi dalam jiwanya agaknya menjadi sidrom yang berkepanjangan. Sindrom keterasingan itu pula yang menyebabkan ia merasa semakin asyik ke dalam kenangan tentang dunia masa kanakkanak di kota Mumbai yang justru memperkaya naratif novelnya, sebagaimana pengakuannya sendiri dalam Grimus (1975), novel perdananya. Ia mengatakan: "merupakan hal yang wajar bagi suatu pengasingan; meletakkan akar ke dalam kenangan." Novel ini mendapat tanggapan publik cukup luas, tapi sayang, yang sedianya novel Grimus ini dimaksudkan untuk meraih penghargaan Sains Fiksi Gollanz, ternyata gagal, obsesinya pun kandas. Tahun 1968, kala ia selesai kuliah dari Cambridge, dan ingin pulang ke Mumbai, India, ternyata keluarganya sudah berpindah ke Karachi, Pakistan, kota 'candradimuka' kaum konservatif. Kondisi Pakistan, apalagi kota Karachi, baginya bagai neraka yang akan memenjarakan obsesinya yang berpaham eksistensialisme, hedonisme, dan anti berpikir konservatif. Namun, ia tak dapat berbuat apapun. Sebagai seorang remaja yang aktif di teater dan bercita-cita menjadi penulis sejak di Cambridge, bakat alami mendorongnya bermain drama berjudul Zoo Story, garapan Edward Albee, untuk acara salah satu stasiun televisi di Karachi. Ia benar-benar kecewa, gara-gara dalam lakon itu ada satu kata haram yang muncul, yakni 'daging babi', berimbas pada pencekalan, pentas drama pun harus bubar. Jelas saja, drama harus disensor, sebab di Pakistan, kata yang berbau haram itu tak boleh diucapkan. Belum lagi salah satu tulisannya yang ia kirimkan ke sebuah majalah kecil di 
Karachi juga terkena sensor. Pakistan memang sangat alergi dengan kata 'daging babi.' Istilah ini bukan hanya sekadar seonggok daging yang tidak berharga, tetapi ada nuansa politis di balik istilah haram itu. Dalam ranah politik seperti inilah, bisa jadi Salman benar-benar merasa asing dengan Pakistan, dunia Bhārat yang terislamkan. Meskipun ia berdalih bahwa justru kata daging babi dalam lakon itu merupakan propaganda paling canggih untuk semangat anti daging babi, tetapi pemerintah Pakistan tidak berterima dan menaruh curiga. (Siswoyo, 1989:81). Persoalan kosakata 'daging babi' ini memang sangat dilarang di dunia pentas seni kebudayaan Pakistan, terutama bila ditayangkan di televisi. Tentu saja, pelarangan yang bernuansa semiotika verbal itu mengacu pada keterjalinan antara produksi budaya dengan konstelasi politik antara Pakistan dan India. Dalam konteks inilah, istilah 'daging babi' yang seharusnya bernuansa terma teologis tiba-tiba mengalami hogere op tracking dan berubah menjadi terma politik. Berkaitan dengan pemanfaatan semiotika verbal tersebut, peneliti mengajukan tiga alasan yang dapat dijelaskan secara hirarkhi, dan barangkali juga Rushdie berpikiran sama ketika menciptakan karyanya. Pertama, konstelasi religi antara Hindu dan Islam. Pada masa perang kemerdekaan melawan Inggris, para pejuang India Raya (sebelum pecah menjadi 3 negara; Pakistan, India, Bangladesh), disibukkan dengan soal 'halal-haram' antara komunitas Muslim dan Hindu berkaitan dengan 'daging babi' versus 'daging sapi.' Kedua komunitas keagamaan saling baku hantam dan menganatema berdasarkan hukum agama masingmasing yang saling ditabrakkan, yakni Fiqh alSunnah yang merujuk pada al-kutub alfiqhiyyah al-mazhabiyyah al-Islamiyyah kontra Veda Smrti, khususnya Mānava Dharmaśāstra ataupun Parāśara Dharmaśāstra. Komunitas Muslim India mengharamkan daging babi, sedangkan komunitas Hindu India mengharamkan daging sapi. Sementara, serdadu Inggris yang kebanyakan warga Muslim dan Hindu India ternyata juga saling berkelahi hanya gara-gara berebutan menghindari penggunaan peluru senapan yang dilumuri minyak daging sapi dan minyak daging babi. Secara politis, tentu saja pihak Inggris terlibat langsung dalam memicu pertikaian keagamaan ini. Kedua, konstelasi politik kebangsaan ras Bhārat. Masyarakat India Raya benar-benar terbelah secara politis akibat dipicu oleh faktor agama, dan pengusiran besar-besaran pun terjadi. Pasca diumumkannya dikotomi negeri Islam dan negeri Hindu di tanah India Raya (Bhārat) oleh elit-elit politik pejuang kemerdekaan yang dimotori oleh Muhammad Ali Jinnah, Jawaharlal Nehru maupun Mahatma Gandhi ternyata memicu gelombang migrasi yang tak bisa dihindarkan. Di belahan India bagian barat, pengusiran terhadap orang-orang Hindu terjadi, begitu juga di India bagian timur; pengusiran terhadap orang-orang Islam tak bisa dielakkan. Secara de jure, muncullah pembagian kekuasaan secara politis di tanah India Raya. Warga Muslim India sebelah barat menyebut tanah kekuasaannya sebagai negeri Pakistan, sedangkan warga Hindu India sebelah timur menyebut tanah kekuasaannya sebagai negeri Hindustan. Meski telah terjadi pembagian kekuasaan secara politis, ditambah lagi dengan kesepakatan "Perjanjian Nehru-Liaquat" antara Pakistan dan India yang mengatur hak-hak kaum minoritas di kedua negara, tetapi tetap saja praktek diskriminasi, intimidasi, dan arogansi kaum mayoritas atas minoritas tetap melembaga, sehingga perlakuan yang tidak adil ini meniscayakan gelombang pengungsi yang tak pernah berhenti (Nasrin, 2003:292). Ketiga, konstelasi politik kebahasaan. Bangsa Pakistan memproklamirkan aksara shahmukhi dan legalitas bahasa Urdu sebagai bahasa nasional. Sementara, bangsa India memproklamirkan aksara devanagari dan legalitas bahasa Hindi sebagai bahasa nasional. Bila bahasa Urdu banyak melestarikan perbendaharaan kosakata Arab sebagai identitas simbol peradaban Islam, maka sebaliknya, justru bahasa Hindi banyak melestarikan perbendaharaan kosakata bahasa Sansekerta sebagai identitas simbol peradaban Hindu. Dengan demikian, fakta politik bahasa tersebut semakin memperkuat identitas 
komunitas yang berbasis keagamaan. Dalam konstelasi politik kenegaraan yang berbasis agama tersebut sebenarnya tidak ada perbedaan yang signifikan antara bahasa Urdu dan Hindi, kecuali hanya dalam dua hal. Pertama, orang Pakistan menyebutnya sebagai 'Urdu Zaband' (bahasa Urdu). Bahasa ini lebih banyak mengadopsi bahasa Arab dan Parsi. Sementara itu, orang India menyebutnya sebagai 'Hindi Bhāsha' (bahasa Hindi). Bahasa ini lebih banyak mengadopsi bahasa Sansekerta. Kedua, bahasa Urdu ditulis dengan menggunakan sistem penulisan aksara Arab-Parsi yang disebut shahmukhi sebagai simbol identitas nasionalisme Islam, sedangkan bahasa Hindi ditulis dengan menggunakan sistem penulisan aksara devanagari sebagai simbol identitas nasionalisme Hindu.

Today, we find the Hindi listed as the official language of India, and the Urdu as that of Pakistan. The former is written in the ancient Sanskrit character, namely the devanagari script, and the latter in the shahmukhi, that is the Persian-Arabic script; but it is at first surprising to find that when one hears them spoken, they sound very much alike, and both much like the "Hindustani." The explanation is to simplify the situation radically that Hindi is Hindustani filled out with borrowings from Sanskrit, while Urdu is Hindustani filled out with borrowings from Persian and Arabic conforming to the religious orientation of the two nations. The political history of both nations, however, reflected the "faith community" as an identity marker. The Hindus in India called the Musalmani-dialect as the "real quasiHindustani, and the Hindu scholars (Pandits) also called it as "Urdu" as a pejorative expression for those who speak "Musalmani-Hindi" (the assimilative power of foreign languages) because this language is actually a product of "imperialism", created by "the foreigners" (MuslimTurks, and Muslim-Persians) as a symbol of state-hegemony in India. The term is perhaps related to the word "Ordu", which is dealing with "camp" of imperialists, like the "camp" (known "Getho") of "dālit community" (lit., oppressed-men, untouchables) in India. If the suppressed men in India used the "Dālit Bhāsa" (lit., oppressedmen language), so also the oppressors (tyrants) in India used the other language, called "Urdu Bhāsa" (lit., camp language) to oppress the people through the hegemony of foreign language. But both bhassha in the paradigm of anthropological linguistic, have different statuses; Dālit Bhāsha was related to the "inferior camp talk", other, Urdu Bhāsha (Pakistans called it Urdu Zaband) was related to the "superior camp talk" which since the beginning, it has already been supported by the Muslim Empire. Again, Brahmins also called Musalmani-Hindi as a "Arabicized Hindi". It means that Urdu is the form of the "other Hindustani" that has not been "Sanskritized", "Aryanized" or "Hinduized" by the Hindu scholars (Pandits) as an attempt to come back to the holy/genuine tradition of Brahminism which is related to the Vedantic culture. Therefore, in the episteme of Hindus, especially in the mind-set of Brahmins which is related to the politic, the status of Hindi is considered more superior than Urdu, it is because of three reasons; (1) the use of Devanagari script as a scripta sacra, (2) the use of Sanskrit words as lingua sacra to enrich Hindi Bhāsa vocabularies than other foreign words, such as Persian/ Arabic, (3) to marginalize the foreign "message" in the Brahmanic culture and Vedic tradition through the power of loanwords of Abrahamic culture. It means 
that the existence of "Hindi", is directly a main gate in reaction against the Islam, or a form of resistance to Arab faith (Ali, 2003:5).

Negeri Pakistan memang bukanlah komunitas yang tepat bagi Salman. Sebab itulah, ia kembali ke Inggris. Dengan keinginan yang gigih, ia menuliskan karya epiknya tentang India, dan di sana ia merampungkan karya keduanya itu, Midnight's Children (1979). Novel ini ternyata mendapat sambutan publik yang luar biasa, sehingga tak salah bila novelnya mendapat anugrah Booker Prize and the James Tait Black Prize yang amat prestisius di tahun 1981. Tak tanggung-tanggung, ia mendapat \$ 10.000 dari novelnya. Dan, pada tahun 1993, novel ini kembali mendapat penghargaan dari The Austrian State Prize for European Literature. Belum lagi apresiasi dari New York Review of Books, majalah kritik sastra terpandang di Amerika. Juga, tak kalah responsifnya dari The New York Times. Inilah langgkah awal obsesinya mulai menggeliat dan 'meledak-ledak.' Berkat pengalaman dunia politik Pakistan yang tidak ramah intelektualitas, Salman mulai menulis karya ketiganya, Shame (1983) sebagai novel batu penjuru yang mengungkapkan tentang karakter politik, kebudayaan, dan agama di Pakistan. Ada fakta menarik dari novel ini yang sengaja mengupas persoalan perselingkuhan antara agama, politik, dan kekuasaan yang memotret benturan komunitas Hindu dan Muslim. Dengan kata lain, novel ini benar-benar menghujat sistem politik Pakistan, sebab Shame ditulis dengan latarbelakang dunia politik di negeri Pakistan yang amat tidak bersahabat. Meski berbau murni politik, Salman justru berbangga. Penerbitan novel Shame ternyata juga meraup keuntungan dollar yang luar biasa. Apalagi novel ini dinominasikan sebagai pemenang dari French Prix $d u$ Meilleur Livre Etranger. Setelah kunjungan muhibahnya di Nicaragua, untuk memenuhi undangan Sandinista Association of Cultural Workers, Salman merampungkan karya yang keempat, The Jaguar Smile (1987), tetapi kurang mendapat sambutan publik. Tak puas dengan Booker Prize, Salman menginginkan hadial Nobel, penghargaan paling bergengsi di jagad sastra. Apalagi media massa Inggris ada yang mencalonkannya menerima hadiah Nobel itu. Dengan kepiawaiannya mengkombinasikan daya imajinatif, kelincahan akrobatiknya memerankan karakter tertentu sebagai artis teater/ film, kelihaiannya bermain catur, aktivis politik yang agak provokatif, dan kecakapannya sebagai "kuli tinta", Salman meledakkan obsesinya untuk kesekian kalinya. Kali ini yang menjadi "korban obsesinya" bukan India atau Pakistan, tapi "agama"; dan justru yang menjadi korban bukan prilaku umat Islam melainkan pembawa ajaran Islam. Ledakan obsesi Shalman, dalam konteks ini, dapat dimaknai sebagai orgasme intelektual yang sebenarnya bisa mengacu pada kecenderungan yang berlapis ganda; (1) obsesi sebagai novelis papan atas dengan cara menulis karya fiktif sebagai medium kepengarangannya, (2) obsesi ideologis dengan cara menghantam paham-paham tertentu tentang Islam yang dianggap lebih memihak pada dogma ortodoksi, (3) obsesi politis dengan membenturkan ranah peradaban pemikiran/ akademis yang dibuktikan dengan cara mengangkat tema 'tokoh sentral' yang kontroversial secara dogmatik dengan alasan untuk mengembalikan pencitraan pejoratif mengenai Islam dan menjadikannya sebagai sumber kebanggaan. Muatan obsesi politis yang muncul dalam novelnya ini ternyata sanggup memadukan pendemonstrasikan polemik politis propaganda dogmatika IslamKristen yang disadapnya dari karya-karya polemik kuno milik Gereja abad Pertengahan yang ditambal sulam dengan unsur seni kreatif sastra, dan hal ini terbukti secara tektual di dalam novelnya. Figur Muhammad yang selama ini dianggap sebagai imitatio Dei yang mengemban Verbum Dei yang dikuduskan, secara membabi buta dilecehkannya dalam kubangan kenajisan dan kebiadaban menurut versi "penceritaannya". Barang kali, inilah novel obsesi Salman Rushdie yang paling 
spektakuler sekaligus menyulut kontroversi publik dibanding novel-novelnya yang lahir sebelum maupun sesudahnya. Apalagi, "booming" novel The Satanic Verses mendapat penghargaan dari The Whitbread Prize for Best Novel sebagai karya novel terbaik di jagad sastra versi Barat. Tidak mengherankan bila novel heboh ini menyedot perhatian dunia sastra global, juga pemimpin agama, termasuk pemimpin tertinggi umat Kristen Katolik (Gereja Latin), Paus Yohanes Paulus II dan pemimpin tertinggi umat Islam Shiah, Ayatullah al-Udzma Ruhullah Khomeini. Meski dihadapkan pada fatwa hukuman mati, obsesinya tak pernah surut; dua tahun berikutnya, ia masih produktif menghasilkan karya-karya lain,di antaranya; Haroun and the Sea of Stories dan Imaginary Homelands: Essay and Criticism, 1981-1991 (1991) yang dinominasikan sebagai pemenang versi Writer's Guild Award. Setahun setelah ia mengumpulkan cerpen-cerpennya dalam East, West, Salman Rushdie meraih penghargaan kembali dari Whitbread Prize dan The European Aristeion Prize for Literature berkat karya terbarunya, The Moor's Last Sigh (1995). Selain itu, Salman juga menulis The Ground Beneath Her Feet dan sebuah karya kritik film, The Wizard of $\mathrm{Oz}^{\prime}$. Namun, di atas semua karyakarya tersebut, The Satanic Verses-lah yang mampu mendongkrak popularitas dan obsesi novelnya. Terbukti, The Satanic Verses juga mendapat penghargaan dari Germany's Author of the Year Award pada tahun 1989. Berkat novel The Satanic Verses ini pula, Salman Rushdie dinobatkan sebagai Honorary Professor in Humanities di "Massachusetts Institute of Technology" (MIT) dan a Fellow of the Royal Society of Literature.

Berpijak pada sederetan karya-karya fiksinya yang selalu mendapat penghargaan sebagai maha bintang kuli tinta, sepertinya Salman Rushdie menawarkan wacana liyan, believed in the holiness of beauty of obsession (menuhankan kecantikan obsesi) yang memuja object d'art dalam karya sastranya, dibandingkan menawarkan cawana religius yang terlembaga, believed in the beauty of
Holiness (memuja kecantikan dari "Keagungan"). Anggitan wacana baru yang bersifat resistensi ini berakibat fatal, agama menjadi bahan mainan. Sebenarnya, obsesi yang lahir dari daya kreatif dan imajinatif Salman sendiri tidak dapat dihakimi sebagai penjahat sastra, tetapi obsesi yang "memperkosa" teks Verbum Dei atau Propheta Ipsisima dengan alasan ziarah kreatifitas imajinatif harus mempertimbangkan aspek juridis dan sakralitas agama, agar tidak terjerembab dalam "wacana imperialisme" gaya baru yang modus operandinya tidak jauh berbeda dengan orthopraxi agama yang seringkali menyimpang dari teksnya. Dalam konteks ini pula, peneliti dapat menyimpulkan bahwa keterasingan/ benturan, atau lebih tepatnya inner conflict dalam jiwanya bukan semata-mata peneliti rujukkan pada perasaan Salman Rushdie saja yang terekam dalam salah satu wawancara atau tulisannya, tetapi juga mengamati dari evolusi karya novelnya. Berdasarkan perkembangan muatan wacana dalam novel-novelnya, Salman Rushdie telah menapaki proses keterasingan/ benturan yang berlapi-lapis yang menyeret dirinya makin berorgasme mencuatkan obsesinya. Pertama, keterasingan dan sekaligus benturan antaragama ketika ia memandang dirinya sebagai Muslim-dālit yang sering menjadi batu sandungan, bahkan mengalami konflik batin di tengah-tengah masyarakat Hindu India. Apalagi sejak usia 13 tahun, dia harus terbuang di negeri asing dalam ranah kultur Barat yang menyuguhkan nilai moralitas yang berbeda dengan kultur Bhārat yang menyebabkan dirinya juga tercerabut dari akar keagamaannya semula (lihat novel Grimus dan Midnight's Children). Karya Salman Rushdi yang berjudul Midnight's Children, dapat dianggap sebagai Indo-English novel in a postmodern era, yang juga banyak mengungkapkan tradisi India (Indian tradition) dan keindiaan (Indianization) yang mengusung kolaborasi budaya amalgam Hindu-Islam. Dalam sebuah esainya, Salman pernah menulis tentang jati diri dan pemikirannya: 
I was born an Indian, and not only an Indian, but a Bombayite Bombay, most cosmopolitan, most hybrid, most hotch-poch of Indian cities. My witing and thought have therefore been as deeply influenced by Hindu myths and attitudes as Muslim ones (Salam Rusdhiee, 1991:412-413).

Dalam karyanya, Midnight's Children tersebut, Salman Rushdie banyak menggunakan kesejajaran dengan The Tin Drum. Namun demikian, novel tersebut juga berceritera tentang mitologi Hindu (DewaDewi Hindu), terutama tentang persona sacra Hinduisme, di antaranya; salah satu dewata Trimurti (Dewa Siwa), tentang dewa Hanuman, dewi Prthiwi dan Arjuna, salah satu tokoh Pandawa dan sekaligus sebagai murid kesayangan Sri Krishna yang diceritakan dalam Bhagavad-Gìtā.

Kedua, keterasingan/ benturan politik yang ia rasakan tatkala bermukim di Pakistan yang seringkali teks agama dijadikan 'bemper' untuk pembenaran kepentingan politik perseteruan bilateral antara Pakistan dengan India. Dengan memintal benang kusut politik bilateral itu, Salman merajut narasi novel Shame dengan apik untuk mengangkat budaya yang dikebiri dengan kepentingan politik praktis dengan mengatasnamakan agama sebagai alat pembenaran. Ketiga, keterasingan/ benturan budaya antara budaya Barat dan budaya Islam di Bhārat. Setelah melalui proses "pembaratan" (westernized) yang hedonistik, sekuler dan liberal yang anti sakralitas, ia kemudian kehilangan imannya. Akibatnya, sakralitas agama diprofankan. Tidak salah bila the History of Islam (Sejarah Islam) digubah dalam model his-story about Islam (kisah tentang Islam menurut versi Salman Rushdie); dan pada saat yang sama, kultur Islam "dibaca", "dipahami" dan "diapresiasi" dengan episteme kultur Barat (lihat novel The Satanic Verses). Apalagi, berkat pandangan ideologi neomodernisme yang dianutnya, Sejarah digambarkan sebagai sebuah wawancara dengan pihak pemenang (lihat Gunew dan
Longley, 2004). Wawancara absurd ini melegalkan arogansi kepentingan kaum elit politisi, dan yang meniscayakan munculnya 3 unsur pembentuk Sejarah; penindas (agent), tertindas (victim), dan strategi penindasan (action), sebab bagaimanapun juga narasi sejarah merupakan politik masa lalu yang didekonstruksi ulang oleh Salman melalui nalar Barat. Melalui ekstase imajinatif, Salman sebagai seorang penulis karya sastra IndoInggris telah mengukuhkan kekuasaan wacana fiksi di atas wacana agama, dan pada saat yang sama, dia telah mendekonstruksi de heilige verstehen (pemahaman suci) yang diprofankan kepada pembaca sebagai wacana liyan untuk menciptakan kisahnya.

\section{Representasi Mahound dalam 'the Satanic Verses'}

Ketika novel The Satanic Verses "booming" di pasaran Eropa, pembakaran terhadap karya kontroversial ini pun juga tak luput dari amukan massa. Januari, 1989, kaum fundamentalis Islam di Bradford, Inggris pun mengamuk, turut membakar novel Salman Rushdie yang menghebohkan itu. Namun, Salman tak bereaksi brutal. Ternyata ia hanya menulis pledoi pada The New York Review of Books, 2 Maret 1989, edisi II. Salman mengatakan:

"Dalam perang kata itu, para wali penjaga kebenaran agama telah mengucapkan sejumlah dusta kepada para pengikut mereka. Misalnya saya dituduh menyebut Muhammad sebagai setan. Ini karena saya memakai kata Mahound, yang beberapa abad yang silam, memang dipakai sebagai istilah yang memburuk-burukkan. Tetapi dalam novel itu saya mencoba dengan segala cara menguasai kembali citra yang negatif, untuk merebut kembali citra yang pejoratif.........untuk mengubah penghinaan menjadi kekuatan, kaum Whigs, Tories, bangsa kulit Hitam, semuanya memilih untuk dengan bangga mengenakan nama 
yang semula diberikan untuk merendahkan mereka; begitu pulalah penyendiri kita yang suka mendaki gunung dan terdorong menjadi nabi itu harus disebut Mahound." (The New York Review of Books, 2 Maret 1989, edisi II.)

Pledoi Salman yang dilansir The New York Review of Books itu sekaligus merupakan affirmasi yang berbalik arah menghantam dirinya sendiri. Tuduhan penghujatan terhadap figur persona sacra, Nabi Muhammad saw, dengan memparodikannya sebagai Mahound, justru tidak dapat dielakkan, sehingga, pembelaannya di hadapan entitas Muslim melalui media cetak dianggap sebagai pledoi yang mandul. Novelnya pun dianggap sebagai kecelakaan intelektual sastrawan yang fatal. Dalam novel The Satanic Verses memang terdapat penanda yang mengarah pada sinyalemen penuh hujatan terhadap Muhammad yang dalam ranah teologi Islam tokoh sentral ini sekaligus dianggap sebagai icon atau pondasi bangunan kebudayaan Islam. Berikut beberapa cuplikan dari teks The Satanic Verses.

"His name: a dream-name, changed by the vision. Pronounced correctly, it means he-for-whom-thanks-shouldbe-given, but he won't answer to that here; nor, though he's well aware of what they call him, to his nickname in Jahilia down below he-who-goes-upand-down-old-Coney. Here he is neither Mahomet nor MoeHammered; has adopted, instead, the demon-tag the farangis hung around his neck. To turn insults into strengths, whigs, tories, Blacks all chose to wear with pride the names they were given in scorn; likewise, our mountain-climbing, prophet-motivated solitary is to be the medieval baby- frightener, the Devil's synonym: Mahound.
That's him. Mahound the businessman, climbing his hot mountain in the Hijaz. The mirage of a city shines below him in the the sun". (The Satanic Verses; chapter II, Mahound, p.93)

"Billy Battuta insisted. 'Fiction is fiction; facts are facts. Our purpose is not to make some farrago like that movie The Message in which, whenever Prophet Muhammad (on whose name be peace!) war heard to speak, you saw only the head of his camel, moving its mouth". (The Satanic Verses; chapter V, A City Visible but Unseen, p.272)

"She falls, coughs, then prostrates herself before him, and says firmly: 'There is no God but Al-Lah, and Mahound is his Prophet.' Mahound calms himself, apologizes extends a hand. 'No harm will come to you,' he assures her." (The Satanic Verses; chapter VI, Return to Jahilia, p.374)

"...........and there was, too, the example of Niccolo Machiavelli to consider (a wronged man, his name, like that of Muhammad-Mahon-Mahound, a synonym for evil; whereas in fact his staunch republicanism had earned him the rack, upon which he survived, was it three turns of the wheel? ..........."

(The Satanic Verses; chapter VII, The Angel Azraeel, p.401)

Dalam novel The Satanic Verses, bab ke-2 Mahound, hlm.93, disebutkan tentang "prophet-motivated solitary is to be the medieval baby-frightener, the Devil's synonym: Mahound. That's him. Mahound the businessman, climbing his hot mountain in the Hijaz. (seorang yang terdorong menjadi nabi, dia adalah sinonim Setan yang sering mengganggu bayi pada abad Pertengahan. Itulah dia. Mahound si pedagang, sedang 
mendaki gunung panas di tanah Hijaz)." Pad bab ke-2 ini, tentu saja dapat terbaca bahwa Rushdie telah menciptakan 'citra tokoh' Mahound sebagai tokoh fiktifnya dengan memanfaatkan tokoh Mahound dalam tokoh historis, sang nabi Islam yang dihujat pada abad Pertengahan. Tentu saja dengan berpijak pada bacaan interteks yang mengacu pada hipogram Mahound dalam tokoh historis tersebut, Rushdie membuat semacam imitasi tokoh dengan model sastra sejarah. Bagi Rushdie, teks novel yang bernuansa sastra sejarah sebagai teks fiksi tersebut, tentu tidak dapat dikatakan sebagai sejarah per se; apalagi teks sejarah sebagai teks fakta yang melawan teks 'sejarah Islam.' Pledoi Rushdie dalam naratif teks novelnya dapat ditelusuri pada bab ke-5. A City Visible but Unseen, hlm.272).

Meskipun pada bab ke-2 tokoh Mahound sebagai tokoh fiktif tidak ada kaitannya dengan Mahound sebagai tokoh historis, tapi pada bab ke-5 ada semiotika verbal dengan menyebut tokoh Muhammad yang dapat dijadikan sebagai 'penanda.' Namun anehnya, pada bab ke-6 Return to Jahilia, hlm.374, Rushdie mulai membuat semacam "benang merah" melalui formula teologis Islam yang dihubungkannya dengan Mahound, tokoh rekaan dalam karya fiksinya. "She falls, coughs, then prostrates herself before him, and says firmly: 'There is no God but Al-Lah, and Mahound is his Prophet." (Hindun jatuh tersungkur, terbatuk, lemah lunglai tak berdaya di hadapan Mahound, dan kemudian dia mengatakan dengan sungguh-sungguh: 'Tidak ada Tuhan selain Allah, dan Mahound adalah utusan-Nya'). Dan, pada bab ke-7 The Angel Azraeel, hlm. 401, Rushdie secara terangterangan "mengumumkan" bahwa yang dimaksud Mahound, yang maknanya sinonim dengan setan itu adalah Muhammad an sich, bukan tokoh lain.

Pada teks yang berkisah tentang Mahound ini, Rushdie memang hanya membuat semacam tokoh ahistoris hasil ciptaan imajinatifnya yang bernama Mahound, seorang pedagang yang tidak lain adalah setan yang sering mengganggu bayi-bayi pada abad
Pertengahan, yang kemudian menjadi seorang nabi di tanah Hejaz. Penokohan Mahound versi Rushdie ini bukan berarti dicipta/ diolah tanpa sumber referensi diakronis. Melalui peletakan wacana sakral yang dikontraskan dengan yang profan, historis melawan ahistoris, Salman berupaya mengukuhkan agenda kristalisasi kuasa wacana fiksi di atas wacana non-fiksi (agama). Selain itu, penggantian atau pun penggeseran wacana publik dari spiritualitas keagaaman menjadi spiritualitas kesusastraan merupakan sebuah wahana representasi ideologi yang mengusung peradaban tunggal yang menginduk ke Barat.

Sebagai seorang intelektual bidang Sejarah lulusan Cambridge, tahun 1964, Salman Rushdie telah banyak "melahap" bukubuku sejarah Islam dan Tarikh Nabi, bahkan dalam salah satu wawancaranya dengan Gerald Marzorati, seorang jurnalis dari The New York Times Magazine, tahun 1989, ia juga mengatakan telah "melahap" buku-buku yang dilarang dalam Islam (Siswoyo, 1989:79). Pengakuan Rushdie ini bukan rekayasa, tapi fakta tekstual yang terekam dalam novelnya. Fakta ini dapat dilihat pada citra tokoh Mahound, yang ternyata Rushdie mengaitkannya dengan frase "the medieval baby-frightener, the Devil's" dan formula shahadat Islam yang diterjemahkan dalam "bahasa Inggris", namun dengan mengubah nama Arab, Muhammad menjadi nama Latin, Mahound. Penggunaan term Muhammad dan Mahound, yakni kedua term yang referensinya merujuk pada tokoh yang sama dalam novel Salman Rushdi, sebenarnya bukan sekadar mempersoalkan nama diri sebagai nomen dalam konstelasi kebudayaan yang berselubung politik keagamaan Arab-Islam dan BaratKristen, tapi sebenarnya, Rushdi juga menggunakan aspek 'permainan bahasa' yang didasarkan pada 'permainan bunyi rima.' Sementara itu, dua kata kunci; Devil dan Medieval sekaligus juga sebagai ekspresi "permainan kata" yang juga berpegang pada "bunyi rima." Selain itu, kedua kata kunci tersebut juga merupakan "dua penanda" yang dapat dipakai untuk menguak misteri kaitan 
antara 3 versi tokoh Mahound; (1) versi Salman Rushdie, (2) versi Bapa-bapa Gereja pada abad Pertengahan dari kalangan Kristen Ortodoks maupun Katolik, dan (3) versi sastrawan pada abad Pertengahan, atau pun era perang Salib.

\section{PENUTUP}

\section{Simpulan}

Berdasarkan penelitian yang dilakukan dapat disimpulkan beberapa hal berikut.

Karya sastra Indo-Inggris yang berakar pada tradisi komunitas dālit identik sebagai pusat kekuasaan di Barat. Tentu saja, karya sastra ini harus dipahami dalam konteks karya sastra pascakolonial yang sekaligus menegaskan posisi Salam Rusdhie sebagai pengarang Indo-Inggris yang 'memuja' episteme Barat dan 'mengebiri episteme Bhārat. Tatkala komunitas itu terdepak dari sistem peradaban Bhārat, maka muncullah paradigma superior dan inferior, ada paradigma budaya asli \& budaya migrasi. Oleh karena itu, benturan peradaban tersebut tidak bisa dihindari.

Pengadopsian narasi-narasi besar (grand-narrative) sebagai wacana sumber yang dikontraskan dengan narasi-narasi kecil (little narrative) dalam karya The Satanic Verses terkuak motif kuasa wacana yang bermaksud untuk meresistrensi dan sekaligus menegasikan tafsiran versi Ashram, yakni kelembagaan Islam di Bhārat. Begitu juga reinterpretasi terma-terma dan narasi Islam yang historis ditundukkan pada langgam kesusastraan yang berjalinkelindan dengan semangat kreatif imajinatif (creatio imaginosus). Anggitan wacana kesusastraan yang tidak lain sebagai the little narrative ini otomatis telah menggeser wacana keagamaan yang tidak lain sebagai the grand narrative. Dengan demikian, resistensi wacana tentang Mahound dalam karya The Satanic Verse yang ditawarkan oleh Salman Rushdie, dalam konteks ini, yang 'pusat' (narasi agama) justru berubah arah menjadi 'pinggiran', sedangkan yang 'pinggiran' (narasi sastra) telah berubah arah menjadi yang 'pusat.'

The Satanic Verses merupakan novel polemik yang interpretasinya ingin menyebal dari 'polisi-polisi pikiran zaman ini' yang fakta sosialnya selalu diinjeksi dengan formula otoritas agama. Selain itu, sebagai karya sastra kosmopolitan yang liberal dan terbaratkan (the westernized liberal cosmopolite), Rusdhie ingin mengisi celah-celah reportase profan dalam wacana teks sakral itu melalui proses desakralisasi yang faktanya berjalin kelindan dengan resiko penghujatan (the blasphemy) terhadap agama Islam.

\section{Saran}

Beberapa permasalahan yang berhubungan dengan novel The Satanic Verses belum terjangkau dalam penelitian ini, terutama berkaitan dengan representasi Ibrahim, penggunaan nama nabi kultur Semit sebagai perampok, nama tokoh Faristha sebagai sebutan malaikat dalam kultur Arya, dan penggunaan nama istri-istri Nabi Islam sebagai pelacur. Oleh karena itu, para peneliti selanjutnya dapat membedah dan mengupas tuntas novel The Satanic Verses karya Salman Rusdhie ini dengan menggunakan teori yang lain.

\section{DAFTAR PUSTAKA}

Ali, Moch. 2003. "Power Behind the Language: Sacred Books and Contextualization." Makalah dipresentasikan dalam forum International Interfaith Conference di Wisma Bumi Asih, Renon, Denpasar, Bali, tanggal 20 Mei 2003.

Appleyard, Brian. 1988. The Sunday Times Magazine, 11 September 1988.

Arquiza, Mucha-Shim \& M. Abdus Sabur (ed.). 2001. Interfaith Conference on the Culture of Peace. Bangkok: Asian Muslim Action Network.

Gunew, Sneja dan Kateryna Longley (ed.). 1992. Striking Chords: Multicultural Literary Interpretation. Sydney: Allen \& Unwin.

Hall, Stuart. 1997. Representation: Cultural Representations and Signifying Practices. London: Sage New Delhi: Thousand Oaks. 
Nasrin, Taslima. 2003. Lajja. terj. Anton Kurnia \& Anwar Holid. Yogyakarta: LKiS.

Salman Rushdie. 1989. The New York Review of Books, 2 Maret 1989, edisi II.

1991. 'In God We Trust', Imaginary Homelands : Essays and Criticism 1981-1991. London: Granta.
1992. The Satanic Verses. Delaware: the Consortium.

Semi, Atar. 1993. Metode Penelitian Sastra. Bandung: Angkasa.

Siswoyo, P. Bambang (et. all). 1989. Heboh Ayat-ayat Setan. Jakarta: UD. Mayangsari. 